\title{
Beyond the limits - ECPR in putative fatal circumstances
}

\author{
Ingo Graeff, MD*; Sylvia Schacher, MD*; Stefan Lenkeit ${ }^{\dagger}$; Catherine N. Widmann, MD $^{\ddagger}$; \\ Jens-Christian Schewe, $\mathrm{MD}^{\dagger}$
}

\begin{abstract}
The eligibility criteria for applying extracorporeal cardiopulmonary resuscitation (ECPR) in patients with cardiac arrest are currently unclear. For those patients with hypothermic cardiac arrest, the European Resuscitation Council (ERC) Guidelines recommend considering ECPR only for patients with potassium $<8 \mathrm{mmol} / \mathrm{L}$ and a body temperature below $32^{\circ} \mathrm{C}$, whereas the American Heart Association Guidelines (AHA) do not express this in a specific manner.

We report the case of an urban unwitnessed out-of-hospital cardiac arrest patient found with her head immersed in water at a temperature of $23^{\circ} \mathrm{C}$. The patient presented an unclear history and a dire combination of clinical and laboratory parameters (asystole, arterial blood gas: $\mathrm{pH} 6.8$, potassium $8.3 \mathrm{mmol} / \mathrm{L}$, lactate $16.0 \mathrm{mmol} / \mathrm{L}$ ). Despite these poor prognostic indicators, ECPR was initiated after 95 minutes of CPR and the patient survived with a good neurological outcome.

This case highlights the uncertainty in ECPR eligibility and prognostication, especially in those with hypothermia and water immersion for whom aggressive therapies may be warranted. Further data and improved strategies are required to delineate candidacy for this resource-intensive procedure better.
\end{abstract}

\section{RÉSUMÉ}

Les critères d'admissibilité aux manœuvres de réanimation cardiorespiratoire avec oxygénation extracorporelle (RCR + OEC) chez les patients ayant subi un arrêt cardiaque sont flous, à l'heure actuelle. En ce qui concerne les patients en état d'arrêt cardiaque hypothermique, la RCR + OEC ne devrait être envisagée que si le taux de potassium est $<8 \mathrm{mmol} / \mathrm{L}$ et si la température corporelle $<32{ }^{\circ} \mathrm{C}$ d'après les lignes directrices de l'European Resuscitation Council, tandis qu'il n'est aucunement fait mention de cette restriction dans les lignes directrices de l'American Heart Association.

Sera exposé ici le cas d'une femme trouvée en état d'arrêt cardiaque, en milieu urbain, extrahospitalier, en l'absence de témoin, qui avait la tête immergée dans l'eau, à une température de $23^{\circ} \mathrm{C}$. La patiente avait des antécédents incertains, et les paramètres cliniques ainsi que les résultats des examens de laboratoire étaient de mauvais augure (asystole; gazométrie du sang artériel : $\mathrm{pH}: 6,8$; potassium : 8,3 mmol/L; lactate : $16,0 \mathrm{mmol} / \mathrm{L}$ ). Malgré ces sombres indicateurs de pronostic, les manœuvres de RCR + OEC ont été entreprises après 95 minutes de RCR, et la patiente a survécu tout en présentant un bon bilan neurologique.
Le cas fait ressortir le degré d'incertitude des critères d'admissibilité à la RCR + OEC et du pronostic, surtout chez les personnes en état d'hypothermie, immergées dans l'eau, chez qui des interventions thérapeutiques énergiques seraient justifiées. Il faudrait donc recueillir davantage de données sur le sujet et élaborer de meilleures stratégies afin de pouvoir départager plus facilement les candidats à cette intervention exigeant beaucoup de ressources.

Keywords: eCPR, urban hypothermia, hyperkalemia

\section{INTRODUCTION}

Extracorporeal life support (ECLS) has been reported as a therapeutic option in refractory cardiac arrest (CA). However, use of this technique has been limited for many years because of availability issues, bleeding risks, and cannulation techniques. Further, questions regarding its effectiveness in this patient group have limited its application. The accessibility of recent miniaturized ECLS devices has led to the expanded use of this therapy ${ }^{1}$ and has, thus far, yielded some encouraging results. ${ }^{2}$ Current cardiopulmonary resuscitation (CPR) guidelines refer to the application of ECPR as an option if initial Advanced Life Support (ALS) efforts are unsuccessful. ${ }^{3,4}$ The AHA 2015 Guidelines do not specifically mention ECPR as an option in patients with accidental hypothermia, ${ }^{3,4}$ and the ERC 2015 Guidelines recommend transport to an ECLS centre. They endorse considering in-hospital ECLS rewarming for patients with a core temperature of $<32^{\circ} \mathrm{C}\left(89^{\circ} \mathrm{F}\right)$ and potassium level of $<8 \mathrm{mmol} / \mathrm{L}$. ${ }^{5}$ Some observational studies have reported an increased number of survivors in this group. ${ }^{6}$ Recommendations

From the ${ }^{*}$ Emergency Department, University Hospital Bonn, Bonn, Germany; ${ }^{\dagger}$ Department of Anaesthesiology and Intensive Care Medicine, University Hospital Bonn, Bonn, Germany; and ¥Department of Neurodegenerative Diseases and Gerontopsychiatry, Bonn, Germany

Correspondence to: Dr. Sylvia Schacher, Emergency Department, University Hospital Bonn, Sigmund-Freud-Strasse 25, 53105 Bonn, Germany; Email: sylvia.schacher@ukbonn.de 
for applying extracorporeal membrane oxygenation (ECMO) in patients with hypothermia have mainly been based on findings that were elaborated from avalanche and drowning victims. ${ }^{6-8}$ It is unclear whether the reported results can be applied to cases of urban hypothermia.

Herein, we will present a case of severe hypothermia and CA in an urban setting. The patient presented with unfavourable factors potentially limiting the use of ECPR. After careful consideration, the team decided to apply ECPR beyond current recommendations.

\section{CASE REPORT}

On a spring morning, a 50-year-old female was discovered in a prone position on a river bank, with her head immersed in the water, and was experiencing a CA of an uncertain origin. Layperson basic life support (BLS) was initiated then stopped, as water was emitted from the mouth during chest compressions. The emergency physician arrived on scene five minutes later and restarted CPR. During the initial survey, an electrocardiogram (ECG) revealed asystole and a concurrent tympanic temperature of $23.0^{\circ} \mathrm{C}\left(73.4^{\circ} \mathrm{F}\right.$; external temperature of $\left.11.0^{\circ} \mathrm{C}\left[51.8^{\circ} \mathrm{F}\right]\right)$. Endotracheal intubation was performed, and end-tidal $\mathrm{CO}_{2}$ measurements up to $4,133 \mathrm{kPa}(31 \mathrm{~mm} \mathrm{Hg})$ during CPR were recorded. The rescue of the patient was difficult as the river embankment was about $6 \mathrm{~m}$ high and was performed with a basket stretcher while the patient was undergoing continuous CPR using an automatic chest compression device (ACCD). The patient was transferred after 35 minutes of on-scene treatment.

The patient arrived at the emergency department (ED) 50 minutes after the commencement of ALS. An initial survey was performed, and a rhythm analysis showed asystole. At that point, the core temperature was $22.8^{\circ} \mathrm{C}\left(73.0^{\circ} \mathrm{F}\right)$. A physical exam, a chest $\mathrm{X}$-ray, and an ultrasound revealed no other reversible causes of CA, apart from hypothermia and hyperkalemia. A physical examination revealed a orbital hematoma on the left side, a string-shaped red mark around the neck, a large hematoma on the right shoulder, and multiple bruises as signs of trauma.

An arterial blood gas analysis (ABG, alpha-stat method) yielded a $\mathrm{pH}$ of $6.8, \mathrm{PaO}_{2}$ of $69.72 \mathrm{kPa}$ $(523 \mathrm{~mm} \mathrm{Hg}), \mathrm{PaCO}_{2}$ of $4.6 \mathrm{kPa}(34.5 \mathrm{~mm} \mathrm{Hg})$, base excess of $-26.9 \mathrm{mmol} / \mathrm{L}$, potassium level of $8.3 \mathrm{mmol} / \mathrm{L}$, and lactate level of $16.0 \mathrm{mmol} / \mathrm{L}$.
After completing the examination, and with the point of care test results at hand, there was an intense interdisciplinary discussion about the feasibility of continuing $\mathrm{CPR}$ as the clinical findings and $A B G$ values did not favour survival based on current knowledge. As signs of irreversible death were lacking and the uncertain course of the preceding events, especially with regard to the sequence of hypothermia and asphyxia, as well as the age of the patient, it was decided to establish venous-arterial ECMO for extended cardiac life support and rewarming. A cardiac ultrasound excluded intracardial thrombi prior to insertion.

ECMO was successfully inserted into the right groin (percutaneous puncture of the femoral vein and artery) 45 minutes after arrival at the hospital. Ninety-five minutes of continuous CPR was carried out until the commencement of ECMO resuscitation. The core temperature at the start of ECMO was $22.4^{\circ} \mathrm{C}\left(72.3^{\circ} \mathrm{F}\right)$. At $27^{\circ} \mathrm{C}\left(80.6^{\circ} \mathrm{F}\right)$, while rewarming the heart rhythm switched to ventricular fibrillation, the patient needed sedation because of gasping and spontaneous breathing. A core temperature of $30.0^{\circ} \mathrm{C}\left(86.0^{\circ} \mathrm{F}\right)$ was attained 53 minutes later. After ruling out intracardial thrombi, successful defibrillation at $200 \mathrm{~J}$ resulted in a prompt sinus rhythm and the return of spontaneous circulation.

Post-resuscitation care was provided that involved only mild therapeutic hypothermia because of the risk of intracranial bleeding. The body temperature during ECLS varied between $33.5^{\circ} \mathrm{C}\left(92.3^{\circ} \mathrm{F}\right)$ upon arrival at the intensive care unit (ICU) and $36.0^{\circ} \mathrm{C}\left(96.8^{\circ} \mathrm{F}\right)$ before decannulation 45 hours later. Neuron-specific enolase was used as a biochemical indicator of neurological prognosis and was determined after 24 and 48 hours, with levels of $37.6 \mathrm{ng} / \mathrm{mL}$ and $57.8 \mathrm{ng} / \mathrm{mL}$, respectively.

Because of the injuries revealed in a trauma computed tomography (CT) scan (fractures of the midface bones, humerus, and clavicle; laceration of the pancreas; and traumatic subarachnoid hemorrhage) and a possible occurrence of a violent felony, police and forensic medicine were involved. Their findings concluded that the patient had jumped approximately six to eight meters from the river embankment with suicidal intention. The fall was determined to have caused most of the injuries, but the pancreas laceration was most likely caused by the (mechanical) chest compressions.

The patient remained in the hospital for one month mainly because of necessary surgical treatment and was then transferred for further psychiatric care. According to chart data at this time, the patient experienced a mild 
impairment in the ability to concentrate and incomplete hemiparesis of the right side (cerebral performance category $[\mathrm{CPC}] 2$ ).

\section{DISCUSSION}

We report on a patient who experienced an urban OHCA and was discovered immersed in water with severe hypothermia. As in many cases with such characteristics, it was not possible to determine the sequence of events with respect to hypothermia, water immersion, and CA. The clinical team elected to initiate ECPR, and the patient survived with a positive neurologic outcome. This case highlights the potential for positive outcomes among those with hypothermia and water immersion, despite the presence of other negative prognostic indicators.

As a cause of CA, accidental urban hypothermia is a rare condition in a moderate climate outside of alpine areas. ${ }^{9}$ Most studies cover rural areas and the wilderness, ${ }^{6,8,10,11}$ and only one study was set in an urban area. ${ }^{9}$ Patients involved in accidents in the wilderness tend to be younger and healthier that are important ameliorating factors for survival. ${ }^{8}$ However, asphyxia is rare in urban settings, as mostly secondary hypothermia occurs because of intoxication, trauma, or stroke. ${ }^{9}$ Neurologic outcomes of surviving patients following hypothermic CA might be good, ${ }^{12}$ as hypothermia enables the brain to tolerate longer no-flow times as oxygen metabolism is substantially reduced. ${ }^{5}$ Especially for such patients who are intoxicated, long-term survival is high, ${ }^{9,12}$ and the neurologic outcome is favourable. ${ }^{9}$

Existing studies have tried to identify the positive and negative indicators of survival and neurologic outcomes. In mountain medicine, asphyxia has been identified as a negative parameter for hypothermic avalanche victims, for example, because of a snow-obstructed airway. ${ }^{13}$ This has been confirmed in Scandinavian studies, showing that drowning victims differ from patients with sole environmental hypothermia: patients with non-asphyxia in whom hypothermia preceded hypoxia had a reasonable prognosis. ${ }^{8,11,12}$ For example, in a report of 11 patients with non-asphyxia on ECLS, 7 $(63 \%)$ survived and could be discharged neurologically intact. $^{11}$

Factors influencing survival after CA in severe hypothermia include age, gender, and serum potassium. Other lab parameters such as $\mathrm{pH}$ and lactate do not seem to have prognostic significance, and the findings on arterial $\mathrm{pCO}_{2}$ have been inconclusive. ${ }^{8-10,14} \mathrm{~A}$ witnessed CA of patients experiencing hypothermia is associated with higher survival rates and favourable long-term neurologic outcomess. ${ }^{9}$ Furthermore, some reports indicate that a low body temperature has a positive impact upon full neurologic recovery. ${ }^{12}$

In the case reported here, arguments for and against the use of ECPR were weighed against the anticipated neurologic outcome. Beneficial for the patient's outcome in this regard was probably her relatively young age and low body temperature of $23.0^{\circ} \mathrm{C}\left(73.4^{\circ} \mathrm{F}\right)$. Additionally, high-quality CPR with an ACCD during transport and sufficient oxygenation might have also contributed positively to the fortunate neurologic outcome.

Adverse factors included CA without witnesses and the unknown length of arrest, in addition to the emission of water from the lungs during initial CPR attempts, indicating at least partial submersion and possible asphyxia. Furthermore, cellular damage signified by high potassium ${ }^{11}$ is an inauspicious finding. In patients who have a hypothermic $\mathrm{CA}$, potassium levels of $>6 \mathrm{mmol} / \mathrm{L}$ are considered a negative predictor for active rewarming with $\mathrm{ECMO},{ }^{10}$ and a potassium level of $>8 \mathrm{mmol} / \mathrm{L}$ is regarded as a contraindication. ${ }^{15}$ In this case, the potassium level was $8.3 \mathrm{mmol} / \mathrm{L}$. To our knowledge, the highest serum potassium reported in an accidental hypothermic adult survivor of OHCA was $7.9 \mathrm{mmol} / \mathrm{L}^{11}$

Applying ECPR to patients with hypothermia experiencing a CA might significantly increase the chances of survival with an auspicious neurologic outcome, as compared with conventional CPR. ${ }^{16}$ Prolonged CPR up to 345 minutes is tolerated before receiving ECLS, with a successful outcome. ${ }^{17}$

The key elements for prognosis have been identified as appropriate coordination of the rescue operation (transportation time and target hospital), immediate highquality CPR (preferably using ACCDs), and application of ECLS for rewarming and cardiorespiratory support, ${ }^{17,18}$ all of which the patient received in this case.

\section{CONCLUSION}

We report the favourable outcome of a patient treated with ECPR after an OHCA in the setting of hypothermia, water immersion, hyperkalemia, and asystole. Our case highlights the potential for favourable outcomes among those with hypothermia-related CA, even in the setting of water immersion and other negative 
prognostic characteristics. Further data and investigation of novel methods are required to better guide clinicians regarding the potential benefit of ECPR management in individual patients with CA.

\section{TAKE-HOME MESSAGES}

1) Consider ECPR in CA, according to current guidelines, specifically in the subcategory of hypothermia.

2) Hypoxia occurring before hypothermia ("dead, then cold") may be a reason to withhold ECLS rewarming.

3) Treatment decisions on a case-by-case basis are advisable as there are no reliable indicators at this time for the treatment and prognosis of patients with (urban) accidental hypothermia.

4) Differences between patients with urban and backcountry hypothermia need to be further elucidated.

Acknowledgements: IG and SS contributed equally to this work.

Competing interests: None declared.

\section{REFERENCES}

1. Riou B, Adnet F, Baud F, et al. Recommandations sur les indications de l'assistance circulatoire dans le traitement des arrêts cardiaques réfractaires. Reanimation 2009;18(5):371-5.

2. Sakamoto T, Morimura N, Nagao K, et al. SAVE-J Study Group. Extracorporeal cardiopulmonary resuscitation versus conventional cardiopulmonary resuscitation in adults with out-of-hospital cardiac arrest: a prospective observational study. Resuscitation 2014;85(6):762-8.

3. Link MS, Berkow LC, Kudenchuk PJ, et al. Part 7: Adult Advanced Cardiovascular Life Support: 2015 American Heart Association Guidelines update for cardiopulmonary resuscitation and emergency cardiovascular care. Circulation 2015;132(18 Suppl 2):S444-64.

4. Lavonas EJ, Drennan IR, Gabrielli A, et al. Part 10: Special circumstances of resuscitation: 2015 American Heart Association Guidelines Update for cardiopulmonary resuscitation and emergency cardiovascular care. Circulation 2015; 132(18 Suppl 2):S501-18.

5. Truhlár A, Deakin CD, Soar J, et al. Cardiac arrest in special circumstances section Collaborators. European Resuscitation Council Guidelines for Resuscitation 2015: Section 4.
Cardiac arrest in special circumstances. Resuscitation 2015;95:148-201.

6. Debaty G, Moustapha I, Bouzat P, et al. Outcome after severe accidental hypothermia in the French Alps: A 10-year review. Resuscitation 2015;93:118-23.

7. Kochanek PM, Dezfulian C. Asphyxial cardiac arrest from drowning: giving E-CPR the cold shoulder. Resuscitation 2015;88:A7-8.

8. Wanscher M, Agersnap L, Ravn J, et al. Outcome of accidental hypothermia with or without circulatory arrest: experience from the Danish Præstø Fjord boating accident. Resuscitation 2012;83(9):1078-84.

9. Schober A, Sterz F, Handler C, et al. Cardiac arrest due to accidental hypothermia-a 20 year review of a rare condition in an urban area. Resuscitation 2014;85(6):749-56.

10. Silfvast T, Pettilä V. Outcome from severe accidental hypothermia in Southern Finland-a 10-year review. Resuscitation 2003;59(3):285-90.

11. Farstad M, Andersen KS, Koller ME, et al. Rewarming from accidental hypothermia by extracorporeal circulation. A retrospective study. Eur $\mathcal{f}$ Cardiothorac Surg 2001;20(1): 58-64.

12. Dunne B, Christou E, Duff O, Merry C. Extracorporealassisted rewarming in the management of accidental deep hypothermic cardiac arrest: a systematic review of the literature. Heart Lung Circ 2014;23(11):1029-35.

13. Brugger H, Durrer B, Elsensohn F, et al. ICAR MEDCOM. Resuscitation of avalanche victims: Evidence-based guidelines of the international commission for mountain emergency medicine (ICAR MEDCOM): intended for physicians and other advanced life support personnel. Resuscitation 2013;84(5):539-46.

14. Danzl DF, Pozos RS, Auerbach PS, et al. Multicenter hypothermia survey. Ann Emerg Med 1987;16(9): 1042-55.

15. Champigneulle B, Bellenfant-Zegdi F, Follin A, et al. Extracorporeal life support (ECLS) for refractory cardiac arrest after drowning: an 11-year experience. Resuscitation 2015;88:126-31.

16. Sawamoto K, Bird SB, Katayama Y, et al. Outcome from severe accidental hypothermia with cardiac arrest resuscitated with extracorporeal cardiopulmonary resuscitation. $\mathrm{Am}$ 7 Emerg Med 2014;32(4):320-4.

17. Darocha T, Kosiński S, Jarosz A, et al. The chain of survival in hypothermic circulatory arrest: encouraging preliminary results when using early identification, risk stratification and extracorporeal rewarming. Scand 7 Trauma Resusc Emerg Med 2016;24:85.

18. Hilmo J, Naesheim T, Gilbert M. "Nobody is dead until warm and dead": prolonged resuscitation is warranted in arrested hypothermic victims also in remote areas-a retrospective study from northern Norway. Resuscitation 2014;85(9):1204-11. 